\title{
Decision-making in advanced heart failure patients requiring LVAD insertion: Can preoperative simulation become the way forward? A case study
}

\author{
Capoccia $\mathrm{M}^{1,2}$, Marconi $\mathrm{S}^{3}$, De Lazzari $\mathrm{C}^{* 3,4}$ \\ ${ }^{1}$ Manchester Heart Centre, Manchester University NHS Foundation Trust, Manchester, UK \\ ${ }^{2}$ Department of Biomedical Engineering, University of Strathclyde, Glasgow, UK \\ ${ }^{3}$ National Research Council, Institute of Clinical Physiology (IFC-CNR), Rome, Italy \\ ${ }^{4}$ National Institute for Cardiovascular Research (I.N.R.C.), Bologna, Italy
}

Received: January 15, 2018

DOI: $10.5430 /$ jbei.v4n2p8
Accepted: June 13, 2018

URL: https://doi.org/10.5430/jbei.v4n2p8

\begin{abstract}
Clinical practice heavily relies on results from randomized controlled trials, which may not reflect completely individual patients. Patient-specific modelling has received increasing attention in recent years. Although still far from clinical application on a daily basis, the potential of this approach is significant. The treatment of advanced heart failure may benefit from a modelling framework to guide device treatment and predict outcome. The role of mechanical circulatory support as a long-term solution is increasing in view of the evolving technology and worsening heart failure patient population. Therefore, a preoperative strategy with the ability to predict the course of events in a simulation setting may be justified. Here we present a heart failure patient discussed at a multidisciplinary team meeting whose outcome was compared with simulations carried out with CARDIOSIM ${ }^{\complement}$ software to investigate the role of this approach as a planning strategy to guide intervention and predict outcome. The clinical decision process is complex and many factors are involved. Patient-specific modelling may have a role to play as part of a preoperative planning strategy with more quantitative evaluation to smooth decision-making.
\end{abstract}

Key Words: Mechanical circulatory support system, Congestive heart failure, Haemodynamic, Software simulation, Mathematical model

\section{INTRODUCTION}

Clinical practice relies heavily on rough estimates, experience and results from clinical trials, which may not be directly applicable to individual patients. ${ }^{[1]}$ A patient-specific modelling approach has been the subject of significant interest in recent years in view of its potential ${ }^{[2,3]}$ although still far from clinical application on a daily basis. ${ }^{[4]}$ Mathematical representation of the cardiovascular system based on pressure-volume (PV) relationship and lumped parameter models can help simulate a wide range of cardiovascular conditions and therapeutic interventions maintaining the ability to run on any personal computer. ${ }^{[5]}$ Their simplicity and versatility makes them suitable for clinical assessment on a daily basis, ${ }^{[6-11]}$ although the successful application of this method requires specific haemodynamics teaching addressed to clinicians. ${ }^{[10-12]}$

The treatment of advanced heart failure may benefit from a

*Correspondence: De Lazzari C; Email: claudio.delazzari@ifc.cnr.it; Address: C.N.R., Institute of Clinical Physiology, Rome, Via Palestro, 32 , 00185 Rome, Italy. 
modelling framework to guide device treatment and predict outcome. The role of a mechanical circulatory support system (MCSS) as a long-term solution is increasing in view of the evolving technology and worsening heart failure patient population. Therefore, a preoperative strategy with the ability to evaluate device suitability and predict outcome in a simulation setting may be justified. A cardiovascular software simulator remains a very useful tool for the analysis of the interactions between a left ventricular assist device (LVAD) and the cardiovascular system. ${ }^{[13,14]}$ Although a three-dimensional (3-D) model is an ideal choice, its computational power is highly demanding and time consuming with limited practical application at present. ${ }^{[15]}$ The use of one-dimensional (1-D) or lumped (0-D) representations where space dependence either relates to the axial coordinate (one-dimensional) or splits the cardiovascular system in compartments (lumped parameter models) ${ }^{[16]}$ may overcome these limitations.

The time-varying elastance model ${ }^{[17-19]}$ is a landmark in cardiovascular modelling despite its limitations when used to reproduce the behaviour of the assisted left ventricle. ${ }^{[20]}$ Significant changes in ventricular elastance (VE) occur during support with a displacement pump. Therefore, the elastancecontractility relationship may not work following the insertion of a second pump in the systemic bed. ${ }^{[20]}$ VE changes also develop with rotary pumps where a rising device flow relates to a constant ventricular end-systolic volume (ESV), a reduction in ventricular end-diastolic volume (EDV) and a high increase in left ventricular pressure leading to increased VE to justify its dissociation with contractility. ${ }^{[20]}$ A linear model remains sufficiently accurate ${ }^{[21-23]}$ and adequate in order to simulate the PV relationship, ${ }^{[24]}$ although cardiovascular multiscale modelling ${ }^{[25]}$ has confirmed the limitations of the time-varying elastance concept in relation to the load-dependence of the end-systolic pressure-volume relationship (ESPVR) highlighting the role of further modelling techniques. ${ }^{[26-29]}$ To address these shortcomings, a nonlinear time-varying theory ${ }^{[30]}$ with modifications including the inter-ventricular septum and continuous flow pump ${ }^{[31]}$ is appropriate. Here a unimodal function represents the ESPVR and the Frank-Starling law, making it suitable for the analysis of ventricular interactions with LVAD. Outlet pump modelling using a linearly flow-dependent resistance or dynamic modelling using a time-varying resistance may be suitable for the analysis of pulsatile and continuous flow LVADs. ${ }^{[32,33]}$ A Lagrange multiplier coupling approach ${ }^{[34]}$ to left ventricular assist device modelling ${ }^{[35]}$ using specific methods ${ }^{[36,37]}$ addresses the interactions between the device inlet and the ventricle at the expense of increased instability at the interface between the fluid and solid meshes. Alternatively, a fluid-solid left ventricular model coupled with a lumped parameter model ${ }^{[38-42]}$ can be optimized with high order interpolation at the fluid-solid boundary and obtain simulations of fluid-solid interaction over a complete cardiac cycle during circulatory assistance. ${ }^{[43]}$ Here we present a heart failure patient discussed during MDT meeting whose outcome was compared to the results carried out with CARDIOSIM C software to investigate the role of this approach as a planning strategy to guide intervention and predict outcome.

\section{MATERIALS AND METHODS}

\subsection{Heart model background}

The software package CARDIOSIM ${ }^{(\mathcal{C}}$ is a numerical cardiovascular simulator based on 0-D models for the representation of patho-physiological conditions. The software can be used for clinical decision-making and for educational purposes. ${ }^{[7]}$ The modularity of the software package CARDIOSIM $\stackrel{C}{ }$ enables to combine the different modules according to the need of the simulation. Some of the modules reproduce the behaviour of several LVADs, ${ }^{[44]}$ IABP, ${ }^{[45]}$ biventricular assist device, biventricular pacemaker ${ }^{[46]}$ and thoracic artificial lung.

The cardiovascular simulator enables the choice between the original and modified time-varying elastance theory ${ }^{[8-10]}$ to model the native atrial and ventricular behaviour. This work is based on the module where the left (right) ventricular elastance $e_{l v}(t)\left(e_{r v}(t)\right)$ depends on the characteristic elastance in systole $E_{l v, s}\left(E_{r v, s}\right)$ and diastole $E_{l v, d}\left(E_{r v, d}\right)$ and an activation function $\bar{e}_{l v}(t)\left(\bar{e}_{r v}(t)\right)$ as follows: ${ }^{[39]}$

$$
\begin{aligned}
& e_{l v}(t)=E_{l v, d}+\left[\frac{E_{l v, s}-E_{l v, d}}{2}\right] \cdot \bar{e}_{l v}(t) \\
& e_{r v}(t)=E_{r, d}+\left[\frac{E_{r, s}-E_{r, d}}{2}\right] \cdot \bar{e}_{r v}(t)
\end{aligned}
$$

with

$$
\bar{e}_{l v}(t)=\bar{e}_{r v}(t)= \begin{cases}1-\cos \left(\frac{t}{T_{T}} \pi\right) & 0 \leq t \leq T_{T} \\ 1+\cos \left(\frac{t-T_{T}}{T_{T E}-T_{T}} \pi\right) & T_{T}<t \leq T_{T E} \\ 0 & T_{T E}<t \leq T\end{cases}
$$

$T$ represents the heart period (ECG signal period), $T_{T E}\left(T_{T}\right)$ coincides with the end ventricular systole (T-wave peak time). The Appendix (Note: The appendix can be obtained from 
the author and the editor) contains a glossary of symbols, parameters and abbreviations. Left (right) ventricular pressure $P_{l v}(t)\left(P_{r v}(t)\right)$ is described using the instantaneous ventricular volume and variable elastance concept as follows: ${ }^{[39]}$

$$
\begin{aligned}
& P_{l v}(t)=P_{l v, 0}+e_{l v}(t) \cdot\left[V^{*}{ }_{l v}(t)-V_{l v, 0}\right] \\
& P_{r v}(t)=P_{r v, 0}+e_{r v}(t) \cdot\left[V^{*}{ }_{r v}(t)-V_{r v, 0}\right]
\end{aligned}
$$

In Eq. (3) $P_{l v, 0}$ and $P_{r v, 0}\left(V_{l v, 0}\right.$ and $\left.V_{r v, 0}\right)$ are the resting left and right ventricular pressures (volumes) respectively, $V_{l v}^{*}(t)\left(V_{r v}^{*}(t)\right)$ is the instantaneous left (right) ventricular free wall volume.

The same approach is used to simulate the behaviour of the atrial chambers, the inter-ventricular (IVS) and the interatrial (IAS) septum.

Using the time-varing elastance model for the interventricular septum, we have the following equation:

$$
e_{s p}(t)=E_{s p, d}+\left[\frac{E_{s p, s}-E_{s p, d}}{2}\right] \cdot \bar{e}_{s p}(t)
$$

where $e_{s p}$ is the IVS elastance, $E_{s p, d}\left(E_{s p, s}\right)$ is the IVS diastolic (systolic) elastance and $\bar{e}_{s p}(t)$ is the activation function as follows:

$$
\begin{aligned}
& \bar{e}_{s p}(t)=\left\{\begin{array}{lr}
1-\cos \left(\frac{t}{T_{R}} \pi\right) & 0 \leq t \leq T_{R} \\
1+\cos \left(\frac{t-T_{R}}{T_{T E}-T_{R}} \pi\right) & T_{R}<t \leq T_{T E} \\
0 & T_{T E}<t \leq T
\end{array}\right. \\
& \left\{\begin{array}{l}
P_{l v}(t)=\left[\frac{e_{s p}(t) \cdot e_{l v}(t)}{e_{l v}(t)+e_{s p}(t)}\right] \cdot\left[V_{l v}(t)-V_{l v, 0}\right]+\left[\frac{e_{l v}(t)}{e_{l v}(t)+e_{s p}(t)}\right] \cdot P_{r v}(t)+\left[\frac{e_{s p}(t)}{e_{l v}(t)+e_{s p}(t)}\right] \cdot P_{l v, 0} \\
P_{r v}(t)=\left[\frac{e_{s p}(t) \cdot e_{r v}(t)}{e_{s p}(t)+e_{r v}(t)}\right] \cdot\left[V_{r v}(t)-V_{r v, 0}\right]+\left[\frac{e_{r v}(t)}{e_{s p}(t)+e_{r v}(t)}\right] \cdot P_{l v}(t)+\left[\frac{e_{s p}(t)}{e_{s p}(t)+e_{r v}(t)}\right] \cdot P_{r v, 0}
\end{array}\right.
\end{aligned}
$$

Rearranging Eq. (9), the instantaneous left (right) ventricular

Equations (10) model the ventricular interactions.

Applying the time-varying elastance theory, the left (right) atrial elastance $e_{l a}(t)\left(e_{r a}(t)\right)$ can be described as:

$$
\begin{aligned}
& e_{l a}(t)=E_{l a, d}+\left[\frac{E_{l a, s}-E_{l a, d}}{2}\right] \cdot \bar{e}_{l a}(t) \\
& e_{r a}(t)=E_{r a, d}+\left[\frac{E_{r a, s}-E_{r a, d}}{2}\right] \cdot \bar{e}_{r a}(t)
\end{aligned}
$$


where $E_{l a, s}\left(E_{r a, s}\right)$ is the characteristic elastance in systole; $E_{l a, d}\left(E_{r a, d}\right)$ represents the characteristic elastance in diastole; $\bar{e}_{l a}(t)\left(\bar{e}_{r a}(t)\right)$ is the activation function described by:

$$
\bar{e}_{l a}(t)=\bar{e}_{r a}(t)=\left\{\begin{array}{lc}
0 & 0 \leq t \leq T_{P B} \\
1+\cos \left(\frac{t-T_{P B}}{T_{P E}-T_{P B}} \pi\right) & T_{P B}<t \leq T_{P E} \\
0 & T_{P E}<t \leq T
\end{array}\right.
$$

In ECG signal $T_{P B}\left(T_{P E}\right)$ is the onset (end) of atrial depolarization.

The left and right instantaneous atrial pressures $\left(P_{l a}(t)\right.$ and $\left.P_{r a}(t)\right)$ are described using the instantaneous atrial volume and elastance concept as follows: ${ }^{[39]}$

$$
\begin{aligned}
& P_{l a}(t)=P_{l a, 0}+e_{l a}(t) \cdot\left[V_{l a}^{*}(t)-V_{l a, 0}\right] \\
& P_{r a}(t)=P_{r a, 0}+e_{r a}(t) \cdot\left[V_{r a}^{*}(t)-V_{r a, 0}\right]
\end{aligned}
$$

$V_{l a}^{*}(t)\left(V_{r a}^{*}(t)\right)$ is the instantaneous left (right) atrial free wall volume; $V_{l a, 0}\left(P_{l a, 0}\right)$ and $V_{r a, 0}\left(P_{r a, 0}\right)$ are the resting left and right atrial volumes (pressures) respectively.

According to the concept of atrial interdependence as previously mentioned, the behaviour of the IAS is described as follows:

$$
e_{A s p}(t)=E_{A s p, d}+\left[\frac{E_{A s p, s}-E_{A s p, d}}{2}\right] \cdot \bar{e}_{A s p}(t)
$$

where $e_{A s p}$ is the IAS elastance, $E_{A s p, d}\left(E_{A s p, s}\right)$ is the IAS diastolic (systolic) elastance.

For the activation function, we have:

$$
\bar{e}_{A s p}(t)=\left\{\begin{array}{lr}
0 & 0 \leq t \leq T_{P B} \\
1+\cos \left(\frac{t-T_{P B}}{T_{P E}-T_{P B}} 2 \pi\right) & T_{P B}<t \leq T_{P E} \\
0 & T_{P E}<t \leq T
\end{array}\right.
$$

When $P_{l a}(t) \neq P_{r a}(t)$ the instantaneous IAS volume $V_{\text {Asp }}(t)$ becomes:

$$
V_{A s p}(t)=\frac{P_{l a}(t)-P_{r a}(t)}{e_{A s p}(t)}
$$

The instantaneous left (right) atrial volume is obtained as follows:

$$
\left\{\begin{array}{l}
V_{l a}(t)=V^{*}{ }_{l a}(t)+V_{A s p}(t) \\
V_{r a}(t)=V_{r a}^{*}(t)-V_{A s p}(t)
\end{array}\right.
$$

From Eq. (13), we obtain:

$$
\begin{gathered}
V_{l a}^{*}(t)=\frac{P_{l a}(t)-P_{l a, 0}}{e_{l a}(t)}+V_{l a, 0} \\
V_{r a}^{*}(t)=\frac{P_{r a}(t)-P_{r a, 0}}{e_{r a}(t)}+V_{r a, 0}
\end{gathered}
$$

Inserting Eqs. (18), (19) and (16) in Eq. (17), we obtain:

$$
\left\{\begin{array}{l}
V_{l a}(t)=\left[\frac{P_{l a}(t)-P_{l a, 0}}{e_{l a}(t)}+V_{l a, 0}\right]+\frac{P_{l a}(t)-P_{r a}(t)}{e_{A s p}(t)} \\
V_{r a}(t)=\left[\frac{P_{r a}(t)-P_{r a, 0}}{e_{r a}(t)}+V_{r a, 0}\right]-\frac{P_{l a}(t)-P_{r a}(t)}{e_{A s p}(t)}
\end{array}\right.
$$

Rearranging Eq. (20), the instantaneous left (right) atrial pressure becomes: ${ }^{[48]}$

$$
\left\{\begin{array}{l}
P_{l a}(t)=\left[\frac{e_{A s p}(t) \cdot e_{l a}(t)}{e_{l a}(t)+e_{A s p}(t)}\right] \cdot\left[V_{l a}(t)-V_{l a, 0}\right]+\left[\frac{e_{l a}(t)}{e_{l a}(t)+e_{A s p}(t)}\right] \cdot P_{r a}(t)+\left[\frac{e_{A s p}(t)}{e_{l a}(t)+e_{A s p}(t)}\right] \cdot P_{l a, 0} \\
P_{r a}(t)=\left[\frac{e_{A s p}(t) \cdot e_{r a}(t)}{e_{A s p}(t)+e_{r a}(t)}\right] \cdot\left[V_{r a}(t)-V_{r a, 0}\right]+\left[\frac{e_{r a}(t)}{e_{A s p}(t)+e_{r a}(t)}\right] \cdot P_{l a}(t)+\left[\frac{e_{A s p}(t)}{e_{A s p}(t)+e_{r a}(t)}\right] \cdot P_{r a, 0}
\end{array}\right.
$$

Equations (21) enable the simulation of the interactions be- work (expanded view in Figure 2) includes the following tween the two atrial chambers.

\subsection{Circulatory numerical model}

Figure 1 shows the electric analogue of the cardiovascular network used for the simulations. The systemic arterial netsections: aortic, thoracic and abdominal. Each section can be modelled by resistance, inertance and compliance (RLC) elements as described in. ${ }^{[3]}$ The venous compartment is described using resistances and compliance $\left(R v s_{1}, C v s, R v s_{2}\right)$ neglecting the inertial forces. ${ }^{[49]}$ 


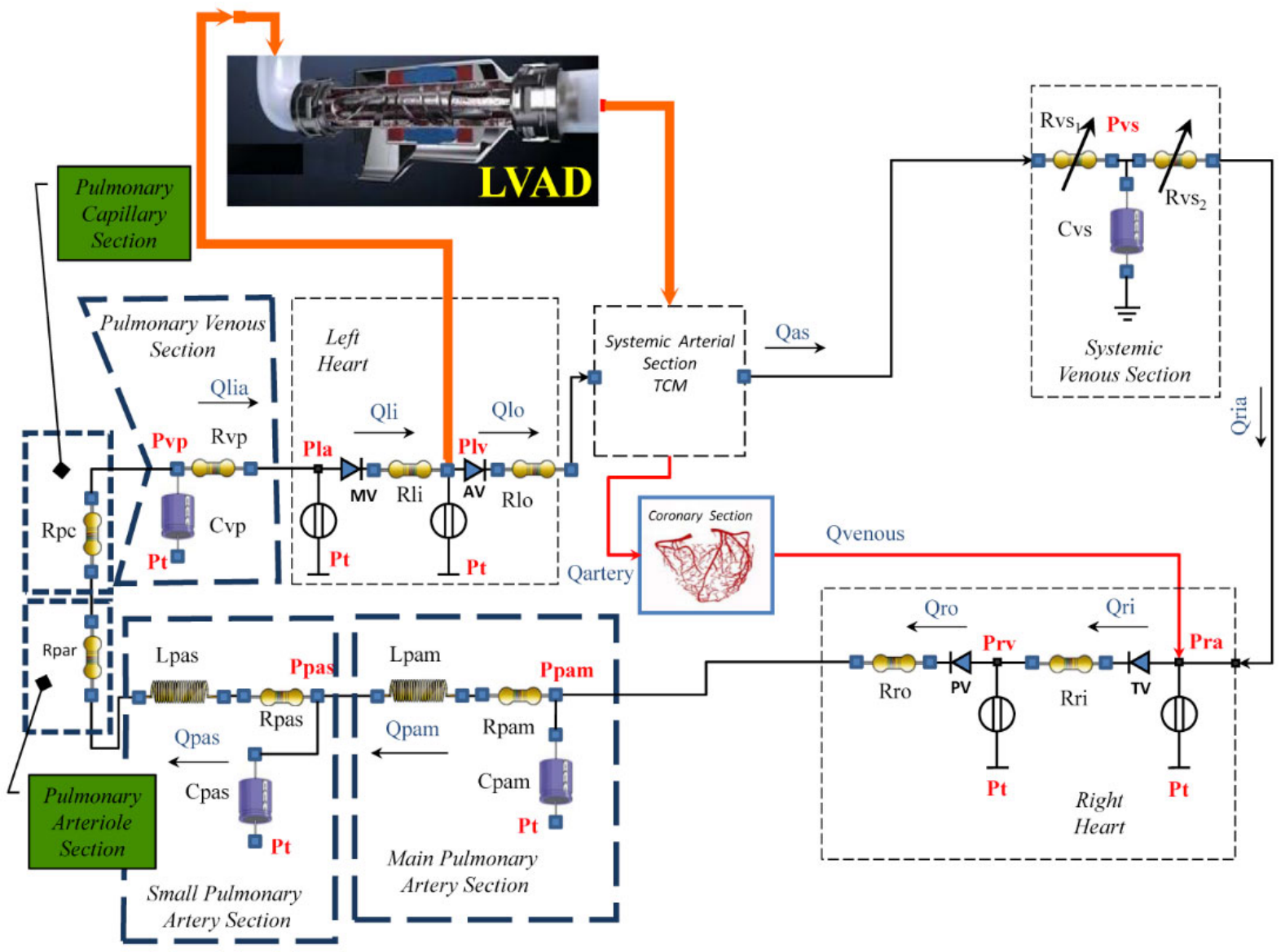

Figure 1. Electric analogue of the cardiovascular network in the presence of LVAD (represented schematically). The behaviour of systemic venous bed is simulated by the compliance Cvs and the variable resistances (Rvs1 and Rvs2). The pulmonary circulation is composed of the main and the small pulmonary artery compartments modelled with RLC elements. The pulmonary arteriole and capillary sections consist of a resistance Rpar and $R p c$ respectively. The pulmonary venous bed is modelled with the resistance $R v p$ and the compliance $C v p$. The LVAD takes blood from the left ventricle and ejects it into the aorta. Coronary circulation network is described in. ${ }^{[6]}$

The intrapulmonary bed and the main pulmonary artery are reproduced using RLC elements (Rpam, Lpam and Cpam). The small pulmonary artery tract consisting of the small intrapulmonary arteries proximal to the arterioles is modelled with Rpas, Lpas and Cpas elements. A single resistance (Rpar) describes the behaviour of the pulmonary arteriole compartment. The behaviour of the pulmonary capillary bed is simulated using a single resistance $(R p c){ }^{[48]}$

The coronary circulation is modelled using one of modules of the CARDIOSIM ${ }^{\mathrm{C}}$ library. ${ }^{[50]}$

The four cardiac valves are considered ideal valves ${ }^{[9,13]}$ and modelled with resistances and diodes. $M V$ diode and $R l i$ ( $A V$ and $R l o$ ) reproduce the behaviour of the mitral (aortic) valve, $T V$ diode and $R r i$ ( $P V$ and $R r o$ ) reproduce the behaviour of the tricuspid (pulmonary) valve. In Figure 1, $P t$ represents the mean intra-thoracic pressure.

The extramural pressure of all the components of the pul- monary circulation and of the lumped elements $A T$ and $T T$ (see Figure 2) is assumed identical to the intra-thoracic pressure, which is a function of time. In our modelling approach, we use instead the mean intra-thoracic pressure defined as:

$$
P t=\frac{1}{T} \int_{0}^{T} p_{t}(t) d t
$$

$T$ is the ventilator cycle duration and $p_{t}(t)$ is the instantaneous value of the time-varying thoracic pressure. The extramural pressure of the blood vessels modelled with lumped elements (in the abdominal compartment and systemic venous section) is equal to the intra-abdominal pressure (the steady state pressure within the abdominal cavity). Here, we assume the extramural pressure of the abdominal compartment and the systemic venous section (see Figure 1) to be identical to the ambient pressure. 


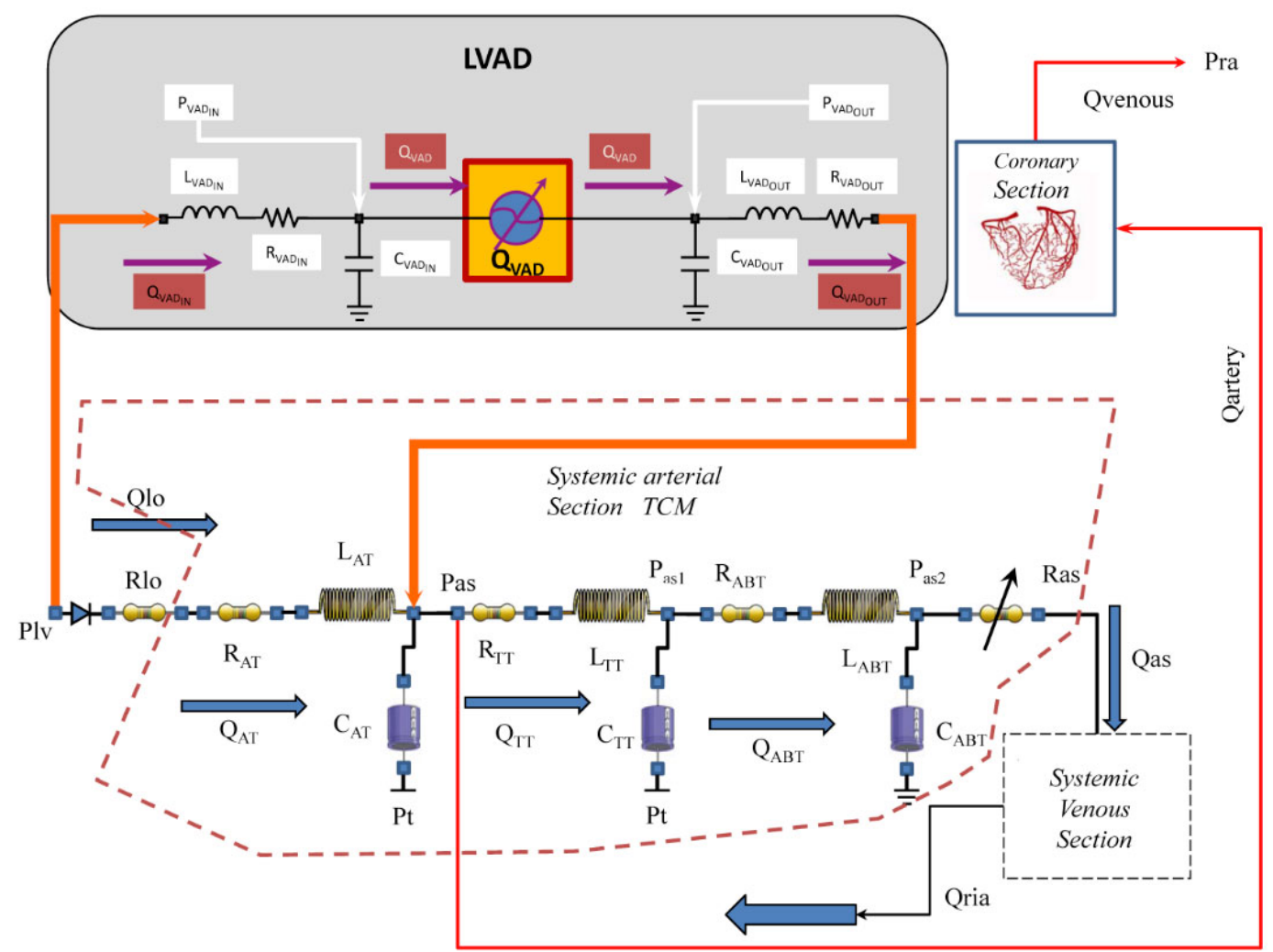

Figure 2. Electric analogue of Berlin Heart INCOR Pump and systemic arterial section. Rvpi, Lvpi and Cvpi (Rvpo, Lvpo and Cvpo) reproduce the behaviour of input (output) cannula. Qvpi and Qvpo represent the input and output flow, through the cannula, from the ventricle (VAD) to the VAD (aorta). The systemic arterial tree is modelled with three RLC elements reproducing the aortic (RAT, LAT, and CAT), thoracic (RTT, LTT, and CTT) and abdominal bed (RABT, LABT, and CABT) respectively. The total systemic vascular resistance consists of a variable resistance (Ras). Qria (Qlo) is the flow directed to the right atrium (left ventricular output flow).

\subsection{Berlin heart INCOR pump numerical model}

The INCOR pump is a ventricular assist device specifically designed for long-term support but it is suitable as a bridge to transplant and bridge to recovery. The blood coming from the left ventricle flows into the device all the way through the inlet guide vane, which ensures a laminar inflow to the rotor. The outlet guide vane behind the rotor generates additional pressure with a specially aligned blade directing the blood in the outlet cannula to the aorta. The rotor produces the required pumping work with a rotational speed between 5,000 and 10,000 rpm. The device creates a constant blood flow, which in combination with the native left ventricle leads to pulsatility in the patient. The electric representation of the LVAD $^{[42]}$ integrated in the cardiovascular simulator is showed in Figure 2. Pressure and flows assume the following equations:

$$
\begin{aligned}
& \left(P_{l v}+P t\right)-P_{V A D_{I V}}=Q_{V A D_{I V}} \cdot R_{V A D_{I V}}+\left(\frac{d}{d t} Q_{V A D_{I V}}\right) \cdot L_{V A D_{I V}} \\
& P_{V A D_{O T T}}-\left(P_{a s}+P t\right)=Q_{V A D_{O U T}} \cdot R_{V A D_{O T T}}+\left(\frac{d}{d t} Q_{V A D_{D O T T}}\right) \cdot L_{V A D_{O U T T}} \\
& Q_{V A D_{N}}=Q_{V A D}+\left(\frac{d}{d t} P_{V A D_{L N}}\right) \cdot C_{V A D_{N}} \\
& Q_{V A D_{O U T}}=Q_{V A D}-\left(\frac{d}{d t} P_{V A D_{O U T T}}\right) \cdot C_{V A D_{O U T}}
\end{aligned}
$$

Both inlet and outlet cannulas are modelled with resistance, inertance and compliane. The INCOR pump flow is modelled as:

$$
\begin{aligned}
& Q_{V A D}=A_{V A D, 0}+\omega \cdot A_{V A A, 1}+A_{V A D, 2} \cdot\left(P_{V A D_{O U T}}-P_{V A D_{I V}}\right)+A_{V A D, 3} \cdot \omega \cdot\left(P_{V A D_{O U T}}-P_{V A D_{N}}\right)+ \\
& +A_{V A D, 4} \cdot \omega^{2} \cdot\left(P_{V A D_{O U T}}-P_{V A D_{N T}}\right)+A_{V A D, 5} \cdot \omega \cdot\left(P_{V A D_{0 U T}}-P_{V A D_{N N}}\right)^{2}+A_{V A D, 6} \cdot \omega^{2} \cdot\left(P_{V A D_{O U T}}-P_{V A D_{N}}\right)^{2}
\end{aligned}
$$


where:

$$
\omega(t)=B_{0}+B_{P} \cdot \sin \left(\frac{2 \pi t}{T}+\varphi\right)
$$

$B_{0}\left(B_{p}\right)$ represents the ventricular assist device speed (amplitude) component; $\varphi$ is the phase difference between VAD pulsation and the heart timing; $T$ is the cardiac cycle duration. The INCOR pump setting and the cannula values are reported in Table 1.

Table 1. Inlet and outlet conduits parameters

\begin{tabular}{lll}
\hline Parameter & Value & Unit \\
\hline$C_{V A D_{I N}}\left[C_{V A D_{\text {OUT }}}\right]$ & $0.1[0.1]$ & $\mathrm{mmHg} \cdot \mathrm{mL}^{-1}$ \\
$R_{V A D_{I N}}\left[R_{V A D_{\text {OUT }}}\right]$ & $0.01[0.01]$ & $\mathrm{mmHg} \cdot \mathrm{s} \cdot \mathrm{mL}^{-1}$ \\
$L_{V A D_{I N}}\left[L_{V A D_{\text {OUT }}}\right]$ & $1.2 \times 10^{-4}\left[1.2 \times 10^{-4}\right]$ & $\mathrm{mmHg} \cdot \mathrm{s}^{2} \cdot \mathrm{mL}^{-1}$ \\
LVAD parameters & & \\
$\mathrm{A}_{\mathrm{VAD}, 0}$ & $-3.0361 \times 10^{-3}$ & $\mathrm{~L} \cdot \mathrm{min}^{-1}$ \\
$\mathrm{~A}_{\mathrm{VAD}, 1}$ & -1.23045 & $\mathrm{~L} \cdot \mathrm{min}^{-1} \cdot \mathrm{rpm}^{-1}$ \\
$\mathrm{~A}_{\mathrm{VAD}, 2}$ & $5.78974 \times 10^{-4}$ & $\mathrm{~L} \cdot \mathrm{min}^{-1} \cdot \mathrm{mmHg}^{-1}$ \\
$\mathrm{~A}_{\mathrm{VAD}, 3}$ & $-5.8777 \times 10^{-8}$ & $\mathrm{~L} \cdot \mathrm{min}^{-1} \cdot \mathrm{rpm}^{-1} \cdot \mathrm{mmHg}^{-1}$ \\
$\mathrm{~A}_{\mathrm{VAD}, 4}$ & $-1.27359 \times 10^{-6}$ & $\mathrm{~L} \cdot \mathrm{min}^{-1} \cdot \mathrm{rpm}^{-2} \cdot \mathrm{mmHg}^{-1}$ \\
$\mathrm{~A}_{\mathrm{VAD}, 5}$ & $2.04834 \times 10^{-10}$ & $\mathrm{~L} \cdot \mathrm{min}^{-1} \cdot \mathrm{rpm}^{-1} \cdot \mathrm{mmHg}^{-2}$ \\
$\mathrm{~A}_{\mathrm{VAD}, 6}$ & $-3.0361 \times 10^{-3}$ & $\mathrm{~L} \cdot \mathrm{min}^{-1} \cdot \mathrm{rpm}^{-2} \cdot \mathrm{mmHg}^{-2}$ \\
\hline
\end{tabular}

The governing equations are first order ordinary differential equations, which have been solved using Euler's method.

\section{CASe history}

In this work, we present a patient with a significant anterior wall myocardial infarction requiring full medical treatment in view of residual severe left ventricular systolic dysfunction with ejection fraction $\mathrm{EF}=27 \%$. Further deterioration required the administration of dobutamine infusion and close monitoring. The presence of significant co-morbidities including high body mass index (BMI) made this patient an unsuitable transplant candidate whereas LVAD insertion remained debatable and unlikely to achieve clinical improvement. Repeated measurements using a Swan-Ganz catheter showed high values of the resistance and pulmonary artery pressures (PA). A reduction of RVSWI suggested the need of MCSS for the right ventricle following INCOR application. The outcome of the multidisciplinary team meeting suggested to continue with pharmacological treatment and palliative care. In Table 2, we have reported the measured parameters with the calculated left ventricular ESV, EDV and VE.
Table 2. Inlet and outlet conduits parameters

\begin{tabular}{|c|c|c|c|c|c|c|}
\hline & \multicolumn{3}{|c|}{ RHC (Admission) } & \multicolumn{3}{|c|}{ RHC (After 4 days) } \\
\hline & Max & Min & Mean & Max & Min & Mean \\
\hline $\mathrm{BP}[\mathrm{mmHg}]$ & $85-90$ & 59 & 69.3 & $85-90$ & 60 & 70 \\
\hline $\mathrm{RA}[\mathrm{mmHg}]$ & 35 & 17 & 29 & 38 & 22 & 32 \\
\hline $\mathrm{RV}$ [mmHg] & 61 & 14 & 38 & 71 & 11 & 44 \\
\hline $\mathrm{PA}[\mathrm{mmHg}]$ & 62 & 30 & 42 & 70 & 38 & 50 \\
\hline PCWP [mmHg] & 36 & 31 & 32 & 35 & 25 & 34 \\
\hline TPG [mmHg] & 10 & & & 16 & & \\
\hline $\mathrm{CO}[\mathrm{L} / \mathrm{min}]$ & 2.7 & & & 2.8 & & \\
\hline $\mathrm{CI}\left[\mathrm{L} / \mathrm{min} / \mathrm{m}^{2}\right]$ & 1.36 & & & 1.4 & & \\
\hline PVR [wood unit] & 3.7 & & & 5.7 & & \\
\hline $\begin{array}{l}\text { RVSWI } \\
{\left[\mathrm{g} / \mathrm{m}^{2} / \text { beat }\right]}\end{array}$ & 2.4 & & & 2.4 & & \\
\hline HR [bpm] & 100 & & & 95 & & \\
\hline $\mathrm{BSA}\left[\mathrm{m}^{2}\right]$ & 1.98 & & & 1.98 & & \\
\hline $\mathrm{EF}$ & $27 \%$ & & & $27 \%$ & & \\
\hline \multicolumn{7}{|l|}{ Estimated values } \\
\hline EDV & $\sim 100 \mathrm{ml}$ & & & $\sim 109 \mathrm{ml}$ & & \\
\hline ESV & $\sim 73 \mathrm{ml}$ & & & $\sim 80 \mathrm{ml}$ & & \\
\hline
\end{tabular}

\section{EXPERIMENTAL METHOD}

Firstly, we aimed to simulate the cardiovascular background of this patient and estimate the left ventricular elastance from the available data. Secondly, the simulations included the analysis of the effects induced by the continuous left ventricular blood pump (Berlin Heart INCOR Pump) to understand the potential benefit on the patient condition. Thirdly, additional simulations included the effect induced by the administration of Milrinone, which is a phosphodiesterase type-3-inhibitor used in the immediate postoperative period to reduce right ventricular afterload and increase myocardial contractility. During LVAD assistance, the effects induced by the drug were simulated increasing myocardial contractility by $5 \%$ and $10 \%$ and reducing pulmonary and systemic vascular resistance by $5 \%$ and $10 \%$.

\section{RESULTS}

Figure 3 shows the screen output from CARDIOSIM ${ }^{\complement}$ software where the patient diseased status has been reproduced based on right heart catheter measurements on admission and after four days since the commencement of inotropic support as listed in Table 2. The "Simulation" column in Table 3 shows the haemodynamic values obtained by the numerical simulator.

A left ventricular PV loop is generated considering the mean aortic pressure $\left(B P \equiv P_{a s}\right)$ as an approximate value for the end-systolic pressure $\left(P_{a s} \approx P_{e s}\right)$ and the left ventricular preload $L A P \equiv P_{l a} \approx P_{e d}$ as an approximate value for the end-diastolic pressure $\left(P_{e d}\right)$ being the left EDV and ESV available. 


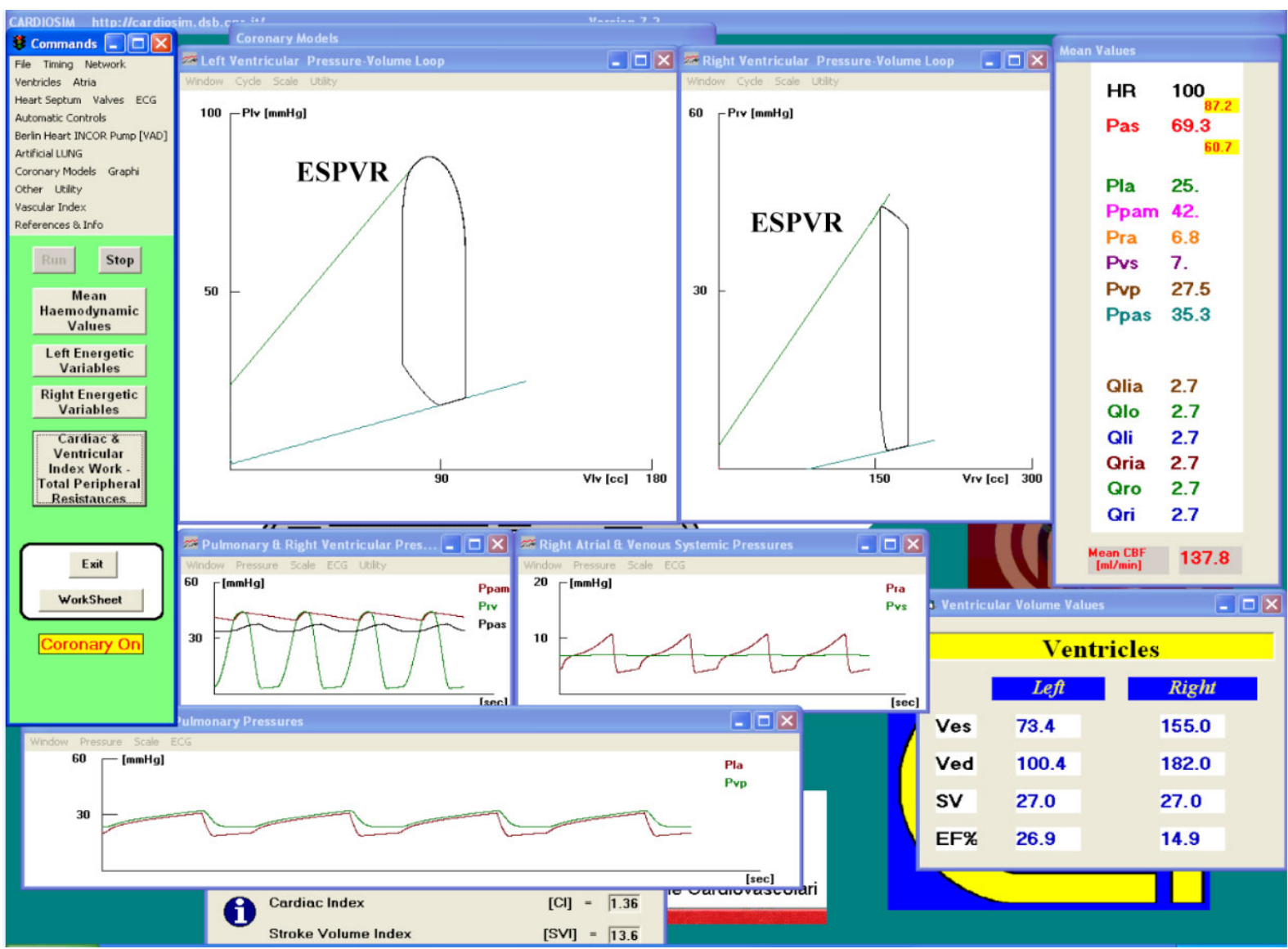

Figure 3. Screen output produced by CARDIOSIM ${ }^{\complement}$ software simulator. The patient clinical diseased status is reproduced in terms of pressure, flow and volume starting with the measured values (RCH Admission in Table 2). The upper left window shows the left PV loop; the right window shows the right PV loop. In this case, the software estimates the slope of left ESPVR at $\sim 0.87\left[\mathrm{mmHg} \cdot \mathrm{cm}^{-3}\right.$ ]. The mean values of pressure and flow are listed in the right column. The systolic, diastolic and mean values for the aortic pressure (Pas) are also listed. The ESV (Ves), the EDV (Ved), SV and the EF are listed under the right column. In the right column HR is the heart rate; Pla (Pra) is the left (right) atrial pressure; Pvs (Pvp) is the systemic (pulmonary) pressure; Ppas (Ppam) is the small (main) pulmonary arterial pressure; CBF is the coronary blood flow. The left column is the command panel of the software.

Consequently, the slope $E_{\max }$ of the left ESPVR can be estimated. A value for $E_{\max } \approx 0.87\left[\mathrm{mmHg} \cdot \mathrm{cm}^{-3}\right]$ was suitable for the patient condition.

A 5\% rise in the total cardiac output $(\mathrm{Qvad}+\mathrm{CO})$ can be observed during LVAD support with reduction of the native left ventricular output from $2.69\left[\mathrm{~L} \cdot \mathrm{min}^{-1}\right]$ to $0.67\left[\mathrm{~L} \cdot \mathrm{min}^{-1}\right]$.

An increase in left ventricular ejection fraction is also observed with a decrease in left ventricular end-diastolic (and end-systolic) volume.

Table 3 shows the simulation outcome following the administration of Milrinone during LVAD assistance. Results listed in the last two columns have been obtained increasing myocardial contractility by 5\% (10\%) and reducing pulmonary and systemic vascular resistance by $5 \%(10 \%)$. The overall outcome of the simulation does not show significant haemodynamic improvement in relation to pressure values with only marginal benefit on cardiac output. Figure 4 shows the left and right pressure-volume loop analysis without and with the mechanical assistance in conjunction with Milrinone administration. The effects induced by drug administration during LVAD support have been simulated increasing myocardial contractility by $10.0 \%$ and reducing pulmonary and systemic vascular resistance by $10.0 \%$. The left and the right pressure-volume loops (left and right side respectively) in the diseased (A) and assisted (B) conditions are available in the two top panels. A leftward shift of the PV loop with a reduction of ESV and EDV is observed for both ventricles during LVAD support and drug administration. The mean value (calculated during the cardiac cycle) of the flow and pressure during LVAD support is available in the right column. 
Table 3. Simulations results without LVAD, with LVAD and with LVAD \& Milrinone

\begin{tabular}{|c|c|c|c|c|c|c|c|c|c|c|c|c|}
\hline & \multicolumn{3}{|c|}{ Simulation } & \multicolumn{3}{|c|}{ LVAD (Simulation) } & \multicolumn{3}{|c|}{$\begin{array}{l}\text { LVAD \& Milrinone } \\
\text { (Simulation) }\end{array}$} & \multicolumn{3}{|c|}{$\begin{array}{l}\text { LVAD \& Milrinone } \\
\text { (Simulation) }\end{array}$} \\
\hline & Max & Min & Mean & Max & Min & Mean & Max & Min & Mean & Max & Min & Mean \\
\hline $\begin{array}{l}\mathbf{B P}[\mathrm{mmHg}]\left(P_{a s}\right) \\
\text { Systemic Arterial } \\
\text { Pressure }\end{array}$ & 87.2 & 60.7 & 69.3 & 75.2 & 62.9 & 68.2 & 77.0 & 64.0 & 69.6 & 78.3 & 64.6 & 70.6 \\
\hline $\begin{array}{l}\mathbf{R V}[\mathrm{mmHg}]\left(P_{r v}\right) \\
\text { Right Ventricular } \\
\text { Pressure }\end{array}$ & 44.2 & - & 20.4 & 43.5 & - & 20.1 & 44.4 & - & 20.5 & 44.6 & - & 20.6 \\
\hline $\begin{array}{l}\text { PA }[\mathrm{mmHg}] \\
\left(P_{a p}\right) \text { Pulmonary } \\
\text { Artery Pressure }\end{array}$ & 44.0 & 39.7 & 42.0 & 43.3 & 38.7 & 40.9 & 44.3 & 39.3 & 41.5 & 44.4 & 39.2 & 42.0 \\
\hline $\begin{array}{l}\text { PCWP [mmHg] } \\
\text { Pulmonary } \\
\text { Capillary Wedge } \\
\text { Pressure }(L A P)\end{array}$ & 31 & 18.7 & 25.0 & 29.6 & 16.8 & 23.1 & 30.4 & 16.8 & 23.3 & 30.6 & 16.4 & 23.5 \\
\hline $\begin{array}{l}\text { HR [beat } / \mathrm{min} \text { ] } \\
\text { Heart Rate }\end{array}$ & 100 & & & 100 & & & 100 & & & 100 & & \\
\hline $\begin{array}{l}\text { EF } \\
\text { Ejection Fraction }\end{array}$ & $26.9 \%$ & & & $31.4 \%$ & & & $33.8 \%$ & & & $36.5 \%$ & & \\
\hline $\begin{array}{l}\text { BSA }\left[\mathrm{m}^{2}\right] \\
\text { Body Surface Area }\end{array}$ & 1.98 & & & 1.98 & & & 1.98 & & & 1.98 & & \\
\hline $\begin{array}{l}\text { CO }\left[\mathrm{L} \cdot \mathrm{min}^{-1}\right] \\
\text { Cardiac Output }\end{array}$ & 2.7 & & & $\begin{array}{l}\mathrm{CO} \\
(0.67)\end{array}$ & $\begin{array}{l}\text { Qvad } \\
(2.15)\end{array}$ & $\begin{array}{l}\text { Qvad+CO } \\
(2.82)\end{array}$ & $\begin{array}{l}\mathrm{CO} \\
(0.75)\end{array}$ & $\begin{array}{l}\text { Qvad } \\
(2.28)\end{array}$ & $\begin{array}{l}\text { Qvad+CO } \\
(3.03)\end{array}$ & $\begin{array}{l}\mathrm{CO} \\
(0.84)\end{array}$ & $\begin{array}{l}\text { Qvad } \\
(2.42)\end{array}$ & $\begin{array}{l}\text { Qvad+C } \\
\text { O (3.26) }\end{array}$ \\
\hline $\begin{array}{l}\text { CI }\left[\mathrm{L} / \mathrm{min} / \mathrm{m}^{2}\right] \\
\text { Cardiac Index }\end{array}$ & 1.36 & & & 0.34 & & & 0.38 & & & 0.43 & & \\
\hline $\begin{array}{l}\text { EDV }\left[\mathrm{cm}^{3}\right] \\
\text { Left Ventricular End } \\
\text { Diastolic Volume }\end{array}$ & 100.4 & & & 89.76 & & & 89.5 & & & 89.12 & & \\
\hline $\begin{array}{l}\text { ESV }\left[\mathrm{cm}^{3}\right] \\
\text { Left Ventricular End } \\
\text { Systolic Volume }\end{array}$ & 73.4 & & & 61.57 & & & 59.2 & & & 56.55 & & \\
\hline $\begin{array}{l}\text { Left ESPVR } \\
{\left[\mathrm{mmHg} \cdot \mathrm{cm}^{-3}\right]} \\
\text { Slope }\left(E_{\max }\right)\end{array}$ & $\sim 0.88$ & & & 0.88 & & & 0.924 & & & 0.968 & & \\
\hline $\begin{array}{l}\text { SVR } \\
{\left[\mathrm{mmHg} / \mathrm{L} \cdot \mathrm{min}^{-1}\right]} \\
\text { Systemic Vascular } \\
\text { Resistance }\end{array}$ & $\begin{array}{l}23.1 \\
{\left[\frac{P_{a s}-P_{r}}{C O}\right.}\end{array}$ & & & $\begin{array}{l}92.95 \\
{\left[\frac{P_{a s}-P_{r a}}{C O}\right.}\end{array}$ & & $\begin{array}{l}22.09 \\
{\left[\frac{P_{a s}-P_{r a}}{Q v a d+C O}\right]}\end{array}$ & $\left.\begin{array}{l}83.73 \\
{\left[\frac{P_{a s}-P_{r a}}{C O}\right.}\end{array}\right]$ & & $\begin{array}{l}20.72 \\
{\left[\frac{P_{a s}-P_{r a}}{Q v a d+C O}\right]}\end{array}$ & $\begin{array}{l}76.3 \\
{\left[\frac{P_{a s}-P_{r a}}{C O}\right.}\end{array}$ & & $\begin{array}{l}19.6 \\
{\left[\frac{P_{a s}-P_{r a}}{Q v a d+C O}\right]}\end{array}$ \\
\hline $\begin{array}{l}\text { TPG [mmHg] } \\
\text { Transpulmonary } \\
\text { Gradient } \\
(P A-P C W P)\end{array}$ & 17 & & & 18 & & & 18.7 & & & 18.5 & & \\
\hline $\begin{array}{l}\text { PVR } \\
{\left[\mathrm{mmHg} / \mathrm{L} \cdot \mathrm{min}^{-1}\right]} \\
\text { Pulmonary Vascular } \\
\text { Resistance }\end{array}$ & $\begin{array}{l}6.3 \\
{\left[\frac{T P G}{C O}\right]}\end{array}$ & & & $\begin{array}{l}26.87 \\
{\left[\frac{T P G}{C O}\right]}\end{array}$ & & $\begin{array}{l}6.38 \\
{\left[\frac{T P G}{Q v a d+C O}\right]}\end{array}$ & $\begin{array}{l}24.93 \\
{\left[\frac{T P G}{C O}\right]}\end{array}$ & & $\begin{array}{l}6.17 \\
{\left[\frac{T P G}{Q v a d+C O}\right]}\end{array}$ & $\begin{array}{l}22.0 \\
{\left[\frac{T P G}{C O}\right]}\end{array}$ & & {$\left[\frac{T P G}{Q v a d+C O}\right]$} \\
\hline $\begin{array}{l}\text { RVSWI [g/m²/beat] } \\
\text { Right Ventricular } \\
\text { Stroke Work Index }\end{array}$ & 6.53 & & & 6.86 & & & 7.33 & & & 7.95 & & \\
\hline
\end{tabular}




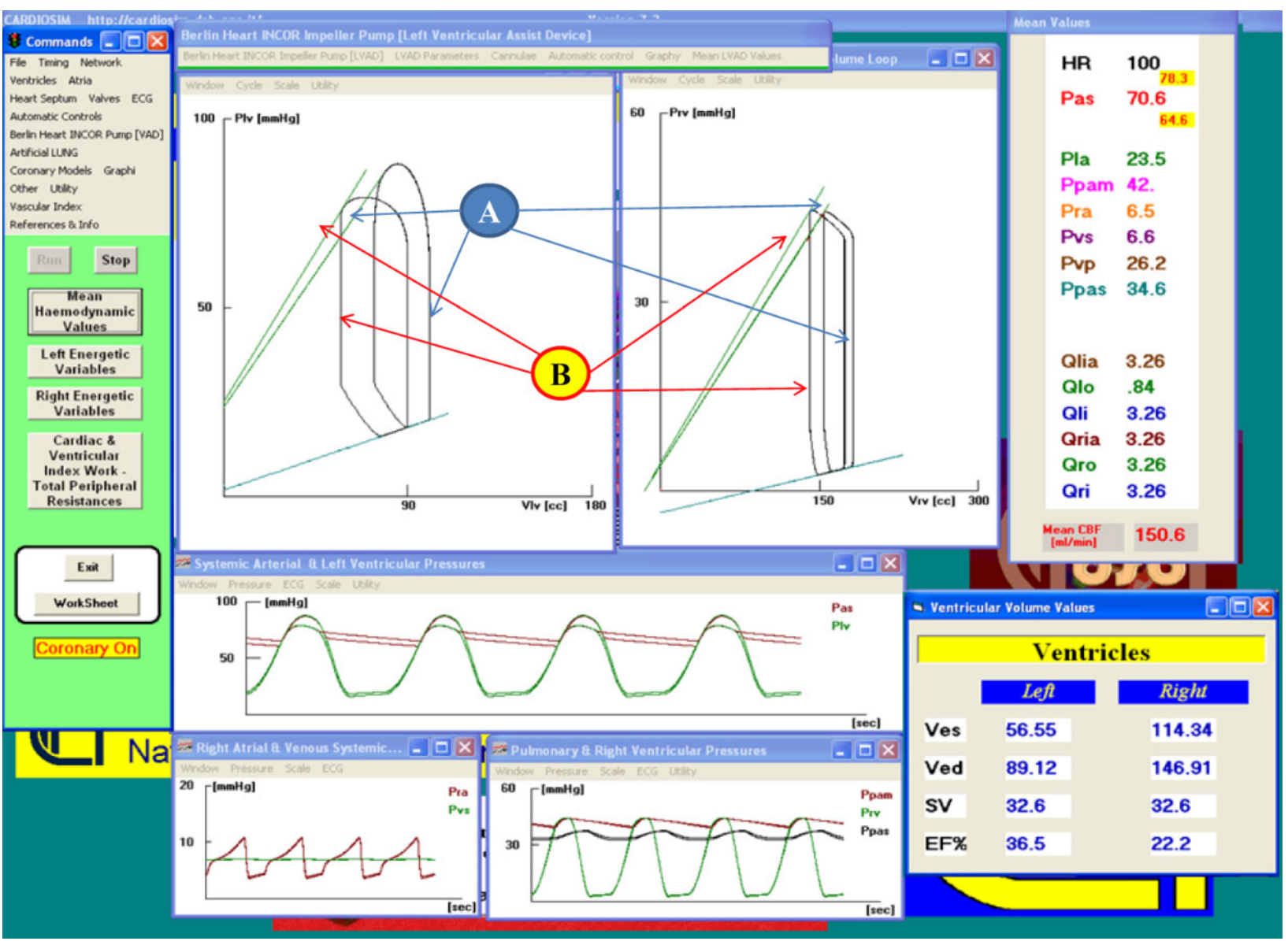

Figure 4. CARDIOSIM ${ }^{\complement}$ screen output where the diseased status and the simulated assistance are plotted. Label A (B) marks the left (left upper panel) and right (right upper panel) ventricular PV loop representing the diseased (assisted) condition. During LVAD assistance, the effects of drug administration were simulated increasing the ESPVR slope and decreasing the systemic and pulmonary vascular resistances.

\section{Discussion}

Interactive software like CARDIOSIM ${ }^{(}$can simulate the cardiovascular system before and after device intervention in real time and in a controlled setting. Examples are the analysis of the interactions with pulsatile and continuous flow LVADs or the IABP. We believe that CARDIOSIM ${ }^{\mathrm{C}}$ is more suitable for clinical application because of its features although we acknowledge the potential of other software like CircAdapt Simulator, HemoLab and Harvi. The CircAdapt Simulator integrates the CircAdapt and TriSeg models ${ }^{[51,52]}$ with a combined adaptation of chambers and vessels in time leading to re-arrangement of the circulation to achieve a steady solution. HemoLab is an integrated computational environment ${ }^{[53,54]}$ where a combination of models can be assembled to obtain the systemic response of the cardiovascular system. Harvi is a cardiovascular simulator-based textbook consisting of a key electrical analogue. ${ }^{[55,56]}$

Patient management in advanced heart failure is very problematic especially when it comes to younger patients. The

Published by Sciedu Press case discussed here is a typical example of difficult decisionmaking where co-morbidities do play a role during the MDT meeting.

The simulation outcome shows a leftward shift of the left and right PV loops with appropriate ventricular volumes and no suction. In contrast, we have to acknowledge that additional improvement occurs over time making INCOR implantation a suitable option. ${ }^{[57]}$ Considering the likely complications associated to the co-morbidities, the MDT outcome may have been appropriate although additional argument to support MCSS is the recent findings about the "obesity paradox", [58] which is currently quite a controversial subject.

A simulation setting is not a replacement of the clinical decision process but an additional tool towards the most suitable treatment. Many factors influence the clinical decision process including previous experience of similar cases, the presence of co-morbidities that may affect the outcome and the risk of potentially fatal complications. 
Although still far from clinical application on a daily basis, there is an increasing recognition shared by clinicians of the potential benefit that patient-specific modelling may bring to the clinical decision process. ${ }^{[59]}$ To increase confidence towards this approach, a larger clinical study would be the way forward to challenge and validate patient-specific simulations.

The heart failure patient discussed in this article is only an example acting as a feasibility approach taking into account its limitation as the only non-blinded scenario. Further work is currently ongoing with the aim to recruit a number of patients for a prospective analysis of our hypothesis.

\section{Conclusion}

Patient-specific modelling may become a daily approach to guide intervention and predict outcome. It is important that simulations provide results that clinicians can understand and rely on. Finally, the medical community needs to raise the awareness and promote the appropriate education to allow further progress of a potentially revolutionary approach in patient care.

\section{ACKNOWLEDGEMENTS}

This work was supported by the Italian Ministry of Education, University and Research (M.I.U.R.) Flagship InterOmics Project (cod. PB05).

\section{REFERENCES}

[1] Kent DM, Hayward RA. Limitations of applying summary results of clinical trials to individual patients: the need for risk stratification. JAMA. 2007; 298: 1209-1212. PMid:17848656. https : //doi.org/10.1001/jama.298.10.1209

[2] Taylor CA, Figuero CA. Patient-specific Modelling of Cardiovascular Mechanics. Annu. Rev. Biomed. Eng. 2009; 11: 109-134. PMid:19400706. https://doi.org/10.1146/annurev.bioeng .10 .061807 .160521

[3] Neal ML, Kerckhoffs R. Current progress in patient-specific modelling. Brief Bioinf. 2009; 2(1): 111-126.

[4] Pedrizzetti G, Domenichini F. Left Ventricular Fluid Mechanics: The Long Way from Theoretical Models to Clinical Applications. Ann. Biomed. Eng. 2015; 43(1): 26-40. PMid:25186434. https: //doi.org/10.1007/s10439-014-1101-x

[5] Doshi D, Burkhoff D. Cardiovascular Simulation of Heart Failure. Pathophysiology and Therapeutics. J. Card. Fail. 2016; 22(4): 303311. PMid:26703246. https ://doi.org/10.1016/j.cardfail .2015 .12 .012

[6] De Lazzari C, Darowski M, Wolski P, et al. In vivo and simulation study of artificial ventilation effects on energetic variables in cardiosurgical patients. Methods of Information in Medicine. 2005; 44(1) 98-105. https://doi.org/10.1055/s-0038-1633928

[7] De Lazzari C, Genuini I, Pisanelli DM, et al. Interactive simulator for e-Learning environments: a teaching software for health care professionals. BioMedical Engineering OnLine. 2014; 13.

[8] Ferrari G, De Lazzari C, Mimmo R, et al. A modular numerical model of the cardiovascular system for studying and training in the field of cardiovascular physiopathology. J. Biomed. Eng. 1991; 14: 91-107.

[9] De Lazzari C, Darowski M, Ferrari G, et al. Modelling in the study of interaction of Hemopump device and artificial ventilation. Computers in Biology and Medicine. 2006; 36(11): 1235-1251. PMid:16202402. https://doi.org/10.1016/j.compbiomed.2005.08.001

[10] De Lazzari C. Interaction between the septum and the left (right) ventricular free wall in order to evaluate the effects on coronary blood flow: numerical simulation. Comput. Methods. Biomech. Biomed. Eng. 2012; 15(12): 1359-1368. PMid:21806416. https : //doi.org/10.1080/10255842.2011.597354

[11] Kozarski M, Ferrari G, et al. Open Loop Hybrid Circulatory Model: The Effect of the Arterial Lumped Parameter Loading Structure on
Selected Ventricular and Circulatory Variables. Biocybernetics and Biomedical Engineering. 2008; 28(1): 17-27.

[12] Fresiello L, Ferrari G, et al. A cardiovascular simulator tailored for training and clinical uses. Journal of Biomedical Informatics. 2015; 57: 100-112. PMid:26173037. https ://doi.org/10.1016/j.jb i. 2015.07.004

[13] De Lazzari C, Darowski M, Ferrari G, et al. The impact of rotary blood pump in conjunction with mechanical ventilation on ventricular energetic parameters: Numerical Simulation. Methods Inf. Med. 2006; 45: 574-583.

[14] De Lazzari C, Ferrari G. Right Ventricular Assistance by Continuous Flow Device. A Numerical Simulation. Methods Inf. Med. 2007; 46: 530-537. PMid:17938774.

[15] Bazilevs Y, Gohean JR, Hughes TJR, et al. Patient-specific isogeometric fluid-structure interaction analysis of thoracic aortic blood flow due to implantation of the Jarvik 2000 left ventricular assist device. Comput. Methods. Appl. Mech. Eng. 2009; 198: 3534-3550.

[16] Peiró J, Veneziani A. Reduced models of the cardiovascular system. Cardiovascular Mathematics. Modelling and simulation of the cardiovascular system, in: L. Formaggia, A. Quarteroni, A. Veneziani (Eds.), Milano Springer-Verlag, 2009. PMid:18763157.

[17] Suga H, Sagawa K. Mathematical Interrelationship Between Instantaneous Ventricular Pressure-Volume Ratio and Myocardial Force-Velocity Relation. Ann. Biomed. Eng. 1972; 1: 160-181. PMid:4668698. https : //doi.org/10.1007/BF02584205

[18] Suga H, Sagawa K, Shoukas AA. Load Independence of the Instantaneous Pressure-Volume Ratio of the Canine Left Ventricle and Effects of Epinephrine and Heart Rate on the Ratio. Circ. Res. 1973; 32: 314-322. PMid:4691336. https://doi.org/10.1161/01.R ES. 32.3 .314

[19] Suga H, Sagawa K. Instantaneous Pressure-Volume Relationships and Their Ratio in the Excised, Supported Canine Left Ventricle. Circ. Res. 1974; 35: 117-126. PMid:4841253. https ://doi.org/ 10.1161/01.RES.35.1.117

[20] Vandenberghe S, Segers P, Steendijk P, et al. Modelling Ventricular Function during Cardiac Assist: Does Time-Varying Elastance Work? ASAIO J. 2006; 52: 4-8.

[21] Stergiopulos N, Meister JJ, Westerhof N. Determinants of stroke volume and systolic and diastolic aortic pressure. Am. J. Physiol. Heart Circ. Physiol. 1996; 270: H2050-H2059. PMid:8764256. https://doi.org/10.1152/ajpheart.1996.270.6.H2050 
[22] Segers P, Stergiopulos N, Westerhof N. Quantification of the contribution of cardiac and arterial remodeling to hypertension. Hypertension. 2000; 36: 760-765. https://doi.org/10.1161/01.HYP.36.5. 760

[23] Segers P, Steendijk P, Stergiopulos N, et al. Predicting systolic and diastolic aortic pressure and stroke volume in the intact sheep. Journal of Biomechanics. 2001; 34: 41-50. https://doi.org/10.101 6/S0021-9290(00)00165-2

[24] Lankhaar JW, Rövekamp FA, Steendijk P, et al. Modeling the Instantaneous Pressure-Volume Relation of the Left Ventricle: A Comparison of Six Models. Annals of Biomedical Engineering. 2009; 37: 1710-1726. PMid:19554450. https://doi.org/10.1007/s1 0439-009-9742-x

[25] Pironet A, Desaive T, Kosta S, et al. A multi-scale cardiovascular system model can account for the load-dependence of the end-systolic pressure-volume relationship. Biomedical Engineering OnLine. 2013; 12: 8. PMid:23363818. https://doi.org/10.1186/1475-925 $\mathrm{X}-12-8$

[26] Luo C, Ramachandran D, Ware DL, et al. Modelling left ventricular diastolic dysfunction: classification and key indicators. Theoretical Biology and Medical Modelling. 2001; 8: 14.

[27] Luo C, Ware DL, Zwischenberger JB, et al. A Mechanical Model of the Human Heart Relating Septal Function to Myocardial Work and Energy. Cardiovasc. Eng. 2008; 8: 174-184.

[28] Olansen JB, Clark JW, Khoury D, et al. A Closed-Loop Model of the Canine Cardiovascular System That Includes Ventricular Interaction. Computers and Biomedical Research. 2000; 33: 260-295. PMid:10944405. https://doi.org/10.1006/cbmr.2000.1543

[29] Chung DC, Niranjan SC, Clark JW, et al. A dynamic model of ventricular interaction and pericardial influence. Am. J. Physiol. Heart Circ. 1997: H2942-H2962.

[30] Ursino M. Interaction between carotid baroregulation and the pulsating heart: a mathematical model. Am. J. Physiol. Heart Circ. Physiol. 1998; 275: H1733-1747. https://doi .org/10.1152/ajpheart .1998.275.5.H1733

[31] Wang Y, Loghmanpour N, Vandenberghe S, et al. Simulation of Dilated Heart Failure with Continuous Flow Circulatory Support. PLoS ONE. 2014; 9(1): e85234.

[32] Huang H, Yang M, Wu S, et al. Dynamic modelling of the outlet of a pulsatile pump incorporating a flow-dependent resistance. Medical Engineering \& Physics. 2013; 35: 1097-1104. PMid:23253954. https://doi.org/10.1016/j.medengphy .2012.11.006

[33] Gohean JR, George MJ, Pate TD, et al. Verification of a computational cardiovascular system model comparing the hemodynamics of a continuous flow to a synchronous valveless pulsatile flow left ventricular assist device. ASAIO J. 2013; 59(2): 107-116. PMid:23438771. https://doi.org/10.1097/MAT.0b013e3182 $7 \mathrm{db} 6 \mathrm{~d} 4$

[34] Nordsletten D, Kay D, Smith N. A non-conforming monolithic finite element method for problems of coupled mechanics. Journal of Computational Physics. 2010; 229: 7571-7593. https: //doi.org/10.1016/j.jcp.2010.05.043

[35] McCormick M, Nordsletten D, Kay D, et al. Modelling left ventricular function under assist device support. International Journal for Numerical Methods in Biomedical Engineering. 2011; 27: 10731095. https://doi.org/10.1002/cnm. 1428

[36] Baaijens FP. A fictitious domain/mortar element method for fluidstructure interaction. International Journal for Numerical Methods in Fluids. 2001; 35: 743-761. https ://doi .org/10.1002/1097-0 363(20010415) 35:7<743: : AID-FLD109>3.0.CD;2-A

[37] van Loon R, Anderson PD, van de Vosse FN. A fluid-structure interaction method with solid-rigid contact for heart valve dynam- ics. Journal of Computational Physics. 2006; 217: 806-823. https : //doi.org/10.1016/j.jcp.2006.01.032

[38] Korakianitis T, Shi Y. Numerical simulation of cardiovascular dynamics with healthy and diseased heart valves. J. Biomech. 2006; 39: 1964-1982. PMid:16140309. https://doi.org/10.1016/j. jbiomech.2005.06.016

[39] Korakianitis T, Shi Y. A concentrated parameter model for the human cardiovascular system including heart valve dynamics and atrioventricular interaction. Med. Eng. \& Phys. 2006; 28: 613-628.

[40] Shi Y, Korakianitis T. Numerical Simulation of Cardiovascular Dynamics With Left Heart Failure and In-series Pulsatile Ventricular Assist Device. Artif. Organs. 2006; 30(12): 929-948. PMid:17181834. https://doi.org/10.1111/j.1525-1594.2006.00326.x

[41] Shi Y, Korakianitis T, Bowles C. Numerical simulation of cardiovascular dynamics with different types of VAD assistance. J. Biomech. 2007; 40: 2919-2933. PMid:17433816. https://doi.org/10.1 016/j.jbiomech.2007.02.023

[42] Shi Y, Brown AG, Lawford PV, et al. Computational modelling and evaluation of cardiovascular response under pulsatile impeller pump support. Interface Focus. 2011; 1: 320-337. PMid:22670203. https://doi.org/10.1098/rsfs.2010.0039

[43] McCormick M, Nordsletten DA, Kay D, et al. Simulating left ventricular fluid-solid mechanics through the cardiac cycle under LVAD support. Journal of Computational Physics. 2013; 244: 80-96. https://doi.org/10.1016/j.jcp.2012.08.008

[44] De Lazzari C, Darowski M, Ferrari G, et al. The influence of left ventricle assist device and ventilatory support on energy-related cardiovascular variables. Medical Engineering and Physics. 1998; 20(2): 83-91. https://doi .org/10.1016/S1350-4533(98) 00008-3

[45] Darowski M, De Lazzari C, Ferrari G, et al. The influence of simultaneous intra-aortic balloon pumping and mechanical ventilation on hemodynamic parameters-numerical simulation. Front. Med. Biol. Eng. 1999; (2): 155-74.

[46] De Lazzari C, D'Ambrosi A, Tufano F, et al. Cardiac resynchronization therapy: could a numerical simulator be a useful tool in order to predict the response of the biventricular pacemaker synchronization. Eur. Rev. Med. Pharmacol. Sci. 2010; 14(11): 968-978.

[47] Maughan WL, Sunagawa K, Sagawa K. Ventricular systolic interdependence: volume elastance model in isolated canine hearts. Am. J. Physiol. Heart Circ. Physiol. 1987; 253: H138-H1390.

[48] De Lazzari C, Quatember B. Cardiac Energetics in Presence of Lung Assist Devices: In Silico Study. Model. Num. Sim. Mater. Sci. 2016; 6: 41-57.

[49] Guyton AC, Jones CE, Coleman TG. Circulatory Physiology: Cardiac Output and its Regulation. In: Computer analysis of total circulatory function and of cardiac output regulation, Philadelphia: W.B. Saunders, 1973.

[50] De Lazzari C, Neglia D, Ferrari G, et al. Computer simulation of coronary flow waveforms during caval occlusion. Methods of Information in Medicine. 2009; 48(02): 113-122.

[51] Arts T, Delhaas T, Bovendeerd P, et al. Adaptation to mechanical load determines shape and properties of heart and circulation: The circadapt model. Am. J. Physiol. Heart. Circ. Physiol. 2005; 288: H1943-H1954.

[52] Lumens J, Delhaas T, Kirn B, et al. Three-wall segment (triseg) model describing mechanics and hemodynamics of ventricular interaction. Ann. Biomed. Eng. 2009; 37: 2234-2255.

[53] Larrabide I, Blanco PJ, Urquiza SA, et al. HeMoLab - Haemodynamics Modelling Laboratory: An application for modelling the human cardiovascular system. Computers in Biology and Medicine. 2012; 42: 993-1004. PMid:22964397. https ://doi .org/10.101 6/j.compbiomed.2012.07.011 
[54] Blanco PJ, Feijóo RA. A dimensionally-heterogeneous closed-loop model for the cardiovascular system and its applications. Med. Eng. \& Phys. 2013; 35: 652-667.

[55] Santamore WP, Burkhoff D. Haemodynamic consequences of ventricular interaction as assessed by model analysis. Am. J. Physiol. Heart. Circ. Physiol. 1991; 260: H146-H157. PMid:1992793. https://doi.org/10.1152/ajpheart.1991.260.1.H146

[56] Burkhoff D, Tyberg JV. Why does pulmonary venous pressure rise after onset of left ventricular dysfunction: a theoretical analysis. Am. J. Physiol. Heart Circ. Physiol. 1993; 265: H1819H1828. PMid:8238596. https://doi.org/10.1152/ajpheart $.1993 .265 .5 . \mathrm{H} 1819$
[57] Capoccia M. Development and Characterization of the Arterial Windkessel and its Role During LVAD Assistance. Artificial Organs. 2015; 39(8): E138-E153. PMid:26147912. https://doi.org/10.111 1/aor. 12532

[58] Mariscalco G, Wozniak MJ, Dawson AG, et al. Body Mass Index and Mortality Among Adults Undergoing Cardiac Surgery: A Nationwide Study With a Systematic Review and Meta-Analysis. Circulation. 2017; 135(9): 850-863. PMid:28034901. https ://doi.or g/10.1161/CIRCULATIONAHA.116.022840

[59] Bluestein D. Utilizing Computational Fluid Dynamics in Cardiovascular Engineering and Medicine - What You Need to Know. Its Translation to the Clinic/Bedside. Artificial Organs. 2017; 41(2): 117121. PMid:28181302. https ://doi .org/10.1111/aor. 12914 